\title{
Positive outcome in obese patients with adolescent idiopathic scoliosis treated with the SpineCor Brace Valerie Vachon ${ }^{1}$, Alin Circo ${ }^{1,2}$, Christine Coillard ${ }^{1,2}$ and Charles H Rivard*1,2
} \author{
Montreal, Canada \\ Email: Charles H Rivard* - chrivard@gmail.com \\ * Corresponding author \\ from 4th International Conference on Conservative Management of Spinal Deformities \\ Boston, MA, USA. I3-16 May 2007 \\ Published: 12 October 2007 \\ Scoliosis 2007, 2(SuppI I):S22 doi:10.1 186/1748-716I-2-SI-S22
}

Address: ${ }^{1}$ Research Center, Sainte-Justine Hospital, 3175 Côte Ste-Catherine, Montréal, Québec, Canada, H3T 1C5 and ${ }^{2}$ University of Montreal,

This abstract is available from: http://www.scoliosisjournal.com/content/2/SI/S22

(C) 2007 Vachon et al; licensee BioMed Central Ltd.

\section{Objective}

To compare outcomes of SpineCor brace treatment [1] in AIS patients who were obese with the outcome in patients of normal weight.

\section{Study design}

From December 1994, 503 patients were treated using the SpineCor brace. One hundred eighty patients have a definitive outcome. The cohort of patients was divided into two groups according to body habitus. Obese patients were defined as those with a body mass index in the $85^{\text {th }}$ percentile or greater [2]. Assessment of brace effectiveness included 1) number of patients whose curves progressed by $\leq 5$ degrees; 2 ) number of patients whose curves progressed by $\geq 6$ degrees; 3 ) number of patients with curves exceeding forty-five degrees at the end of treatment; and 4) number of patients who have been recommended/undergone surgery before skeletal maturity.

\section{Results}

The results demonstrate that AIS patients who are obese as well as patients of normal weight, treated by the SpineCor brace, have a positive outcome $(62 \%$ and $66 \%$ of success respectively). This is not the case for overweight AIS patients following orthotic treatment using the three point pressure principle [3].

\section{Conclusion}

The results suggested that the use of a dynamic brace to improve scoliotic deformations through a new concept and treatment approach re-establishes spinal function, while preserving body movement and growth without being interfered by body habitus.

\section{References}

I. Coillard C, Leroux MA, Badeaux J, Rivard CH: SPINECOR: a new therapeutic approach for idiopathic scoliosis. Stud Health Technol Inform 2002, 88:215-217.

2. Dehghan M, Akhtar-Danesh N, Merchant AT: Childhood obesity, prevalence and prevention. Nutrition Journal 2005, 4:24.

3. O'Neill PJ, Karol LA, Shindle MK, Elerson EE, BrintzenhofeSzoc KM, Katz DE, Farmer KW, Sponseller PD: Decreased orthotic effectiveness in overweight patients with AIS. Bone Jt Surg 2005, 87A: 1069-1074. 